\title{
SUBCUTANEOUS GLUCOSE BIOSENSOR FAILURE - A FUZZY FAULT TREE ANALYSIS APPROACH
}

\author{
C. G. SIONTOROU \& F. A. BATZIAS \\ Department of Industrial Management \& Technology, University of Piraeus, Greece.
}

\begin{abstract}
Diabetes mellitus is a disease of major global importance, increasing in frequency at almost epidemic rates. In order to optimize diabetes management and, therefore, reduce hyper- or hypo-glycaemia complications, continuous and reliable in vivo (subcutaneous or intravenous) glucose monitoring is indispensable. To that end, subcutaneous sensors have progressed more rapidly as they can be linked to state-of-the-art signal transmission modes (transdermal, IR, etc.). Yet, most of the devices currently at clinical trials have not demonstrated a stable and clinically useful sensor performance. In this work, the causes of subcutaneous glucose biosensor sensitivity drift have been investigated by means of fault tree analysis relying on fuzzy reasoning to account for uncertainty. Using the methodology proposed herein, all ultimate causes or combination of causes attributed to the device components, the surrounding tissue and their intra/inter-relations that are responsible for or contribute to the top event have been recognized and quantified based on (a) measurements for the deterministic contributors and (b) experience for the stochastic contributors. The tree structure has been designed by combining deduction and induction, top-down and bottom-up techniques, thus establishing a dialectic tradeoff which brings this method closer to scientific logic, permitting the introduction of deeper knowledge into the surface or experiential knowledge level characterizing FTA. The proposed methodology has been implemented in the investigation of the causes responsible for sensor fouling by thrombus formation and has proven to be an efficient tool for internal diagnostics and fault compensation. The suggested approach may contribute significantly to the self-optimization of the measuring equipment from one generation to the next as it supports the flexible, ad hoc, and tailor-made development, thus potentiating the progress of epidemics from statistics to individualization.
\end{abstract}

Keywords: Biosensors, fault tree analysis, fuzzy logic, knowledge processing, knowledge representation, sensitivity decrease, subcutaneous monitoring.

\section{INTRODUCTION}

Glucose is a major source of energy for cells, and it is transported to cells via insulin in the blood stream. The human body regulates blood glucose at a concentration range of $4-8 \mathrm{mM}$ (70-120 mg/dL); in the presence of physiopathological conditions, the range can extend to $2-30 \mathrm{mM}$ $(30-500 \mathrm{mg} / \mathrm{dL})$. Diabetes is a metabolic disease, resulting in abnormal blood glucose levels and, consequently, in the activation of several metabolic pathways related to inflammation and apoptosis events [1]. Long-term adverse effects of glucose deregulation have been well documented, representing a leading cause of mortality and several complications to retina, circulatory system and kidneys. According to Shaw et al. [2], the world incidence of diabetics was $6.4 \%$ in 2010 , expected to rise to $7.7 \%$ by 2030 .

To manage diabetes and, therefore, reduce hyper- or hypo-glycaemic complications, much research effort and funding are devoted to the development of smart diagnostic tools [3, 4]. Accurate and systematic glucose monitoring is a key element for allowing patients to keep their glucose levels under control and for providing physicians with a more accurate and detailed picture of the disease. The available self-monitoring devices based on discrete measurements, apart from causing patients' discomfort, do not allow an overall, clear and in-depth view of the actual glycaemic status, especially in type I diabetics, where glycaemia may undergo rapid changes [5, 6]. Continuous in vivo glucose monitoring would improve diabetic control, especially in less-apt individuals (young, 

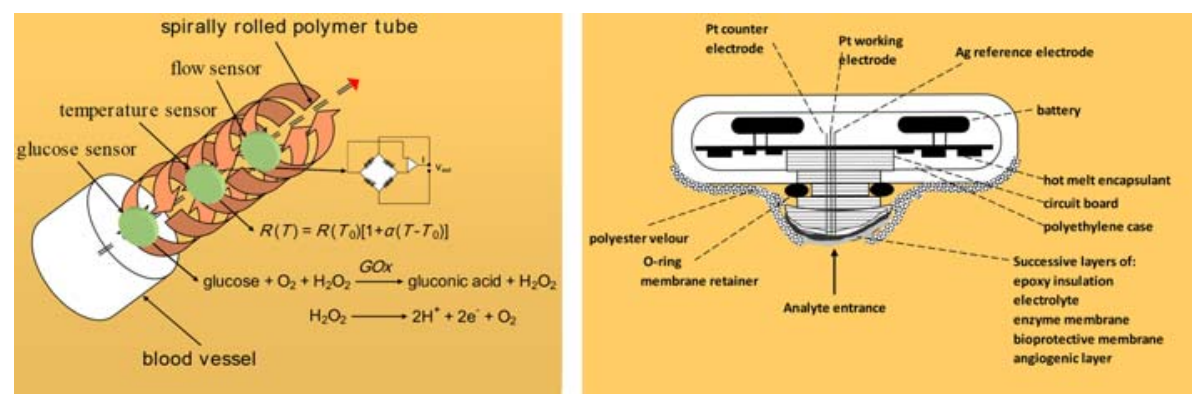

Figure 1: Schematic diagram of intravenous (left) and subcutaneous (right) glucose sensors.

elderly, mentally challenged, etc.) [6]. It could also provide valuable information to R\&D regarding in vivo kinetic parameters after lunch, during sleep or exercise, etc.; this could be the first step towards a completely closed-loop control system that automatically monitors and maintains euglycaemia (artificial pancreas) [7].

Numerous implantable miniaturized sensors are being developed, mostly on the electroenzymatic approach [5,6]; based on polarographic principles, these devices utilize the oxidation of glucose by glucose oxidase and measure amperometrically or potentiometrically the reduction of the produced hydrogen peroxide (Fig. 1). Implantable sensors have been thus far plagued to various degrees and extents by problems of prolonged lag between blood and interstitial fluid glucose levels during dynamic glucose fluctuations, inadequate accuracy, safety concerns, and/or poor portability [8]. Only subcutaneous sensors have reached a sufficient level of performance for several products during clinical trials, mainly from Medtronic Diabetes, Abbot, and Dexcom [9].

For subcutaneous operation, the sensors are designed with standard integrated circuit microfabrication processes; all signal processing can be accomplished on-board the chip, and the entire package is not more than a few square millimetres in size (Fig. 1); the signal is transmitted to an ex vivo recorder by state-of-the-art modes (transdermal, IR, etc.). Unfortunately, the response of these devices undergoes a significant decrease when exposed to in vivo biological environment, attributed vastly to biocompatibility issues (inflammation, fibrosis, scar formation, clot formation in blood vessels, other tissue reactions $[10,11]$ ), and biofouling (excessive protein deposition clogging the sensor's membrane pores with proteins resulting in a decrease or cessation of the flow of molecules to the sensor [12-14]), although sensor corrosion [15, 16], along with the inherent sensor pitfalls (mainly problems associated with the biorecognition/transducer interface [16]) have been frequently reported. Nonetheless, the clinical trials made apparent that the in vivo performance of the sensors differs significantly than the ex vivo one, making calibration difficult, usually expressed as a rapid and significant sensor drift $[17,18]$; current research is focused towards automatic calibration upon insertion, a procedure that could potentially ensure the accuracy of the sensor's data output.

In view of (i) the inter-disciplinary and diverse nature of the subject, involving a merging between the fields of biochemistry, engineering, human physiology, and electronics, (ii) the complexity presented by the specific application, and (iii) the severity of the application, these devices require, inevitably, an intelligent system for real-time fault detection and, preferably, fault compensation, as well, an area that has not received yet much attention. The real-time response of such a system is imperative when considering that misleading glucose readings may result in inappropriate drug delivery that could stimulate vicious feedback cycles, threatening the life of the patient (e.g. severe hypoglycaemic episodes) [1, 8]. 
The identification of the possible sensor fault modes and their symptoms is a prerequisite for constructing such a system, requiring in-depth knowledge of sensor's design and operation, both from the electrochemical and the physiological/biochemical point of view. The most usual and critical fault mode in subcutaneous biosensors is sensitivity drift, which results to either an inaccurate measurement or a dead sensor [16]. The environment within which the sensor operates, involving complex multi-component chemical interactions and exhibiting intricate multi-phase microstructures, increases uncertainty manifold, since there could be (and usually are) many influences acting simultaneously or consecutively, masking, partially or totally, the identification of the problem source. However, diagnosis usually depends on symptomatology and not on aetiology, i.e. the actual measurement of the variables/parameters associated with the problem (online or offline); thus, any misfunction may be realized when its impact becomes critical and not when it arises, making online rectification impossible, at least at a degree that could ensure both patient's well being and sensor functionality.

There have been several attempts for understanding the possible failure mechanisms responsible for the poor in vivo performance of subcutaneous sensors, but still there is no clinical concept available and more insight is required in the physiological processes at the sensor-tissue interface. Limited information and high uncertainty has been successfully handled in certain biomedical cases with fuzzy logic [19, 20]. Fuzzy sets theory provides a way to use imprecise and uncertain information generated by the environmental system and the human judgement in a satisfactory way, in cases where absolute criteria should be avoided and the intuitive aspects of the experts' judgment should be preserved [16, 21-23]. The work presented herein investigates the causes of subcutaneous biosensor sensitivity reduction by means of fault tree analysis (FTA), using the information provided by the biosensor components, the surrounding tissue, and their intra/inter-relations on both the surface- and the deep-knowledge level, simulating an expert system, where the tree (dendritic) structure (with the corresponding to each node appropriate confirmation tests and remedial proposals/advices) serves as the Knowledge Base (KB) and the fuzzy rules based decision mechanism on aetiology is the inference engine.

\section{METHODOLOGY}

The methodology developed by the authors relies mainly on the design/development of a hierarchical structure capable of performing FTA within a framework incorporating (a) the trunk of the SNR-decrease fault tree (i.e. the content part of the fault analysis) and (b) a mechanism of (i) assigning fuzzy partition of the space of the variables represented by each tree node and (ii) setting/ revising of fuzzy rules used as an inference engine (i.e. the formal part of fault analysis).

\subsection{The formal algorithmic part}

The algorithmic procedure especially designed and implemented for computer-aided subcutaneous biosensor fault diagnosis includes 20 activity stages and 7 decision nodes, as described below; for their interconnection, see Fig. 2.

1. Analysis of the system (i.e. the measurand and the measuring components) within the corresponding physicochemical environment.

2. Determination/identification of the top event.

3. Collection of possible causes of the top event, utilizing existing information from in vitro experiments, clinical trials, and case studies.

4. Rational tree design by deduction. 


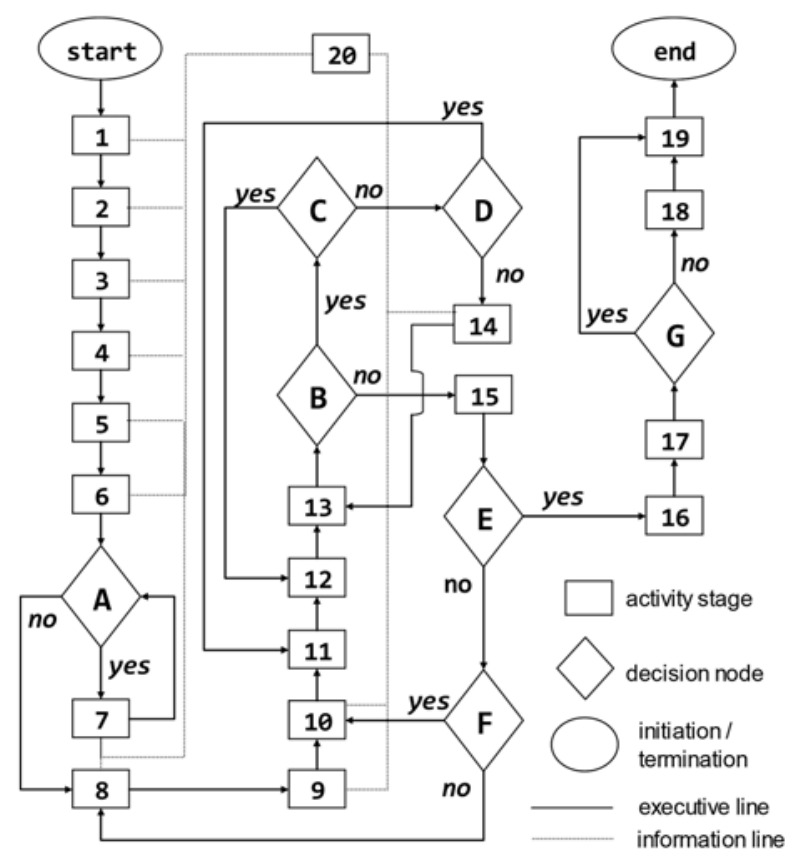

Figure 2: Overview of the algorithmic procedure for performing FTA in subcutaneous sensors.

5. Collection of information concerning other variables/parameters/constraints related to the nodes of the tree.

6. Confirmation of the tree structure (content and architecture) by induction.

7. Extension of the tree and its scientific basis.

8. Fuzzy partitioning of the space of the variables representing each node of the tree.

9. Determination of the fuzzy rules.

10. Estimation of a threshold (maximum tolerable) value, $T$, for the top event.

11. Listing of (remaining) combinations of final events that may produce the top event; ranking of them according to decreasing influence on the top event.

12. Listing of combinations (constituting the antecedent or IF-part) of fuzzy rules that belong to the same combination of final events; ranking of them according to decreasing influence on the top event.

13. Running of the fuzzy FTA bottom-up algorithm for the combinations suggested in stage 12 to find out the top event value as a crisp number (after defuzzification).

14. Reforming of the fuzzy rules, where necessary.

15. Trial to limit the range of values of the most influencing combination of variables to achieve lower value (compared with the threshold) of the top event.

16. Selection of suitable substitutes.

17. Laboratory testing of the device to verify conformity to specifications.

18. Re-engineering of the device and ex vivo validation.

19. Report compilation and forwarding to clinical development if ex vivo development is rendered satisfactory (as per sensitivity, accuracy, stability, and calibration).

20. Creation/enrichment of the internal KB. 
A. Is the addition of new nodes and/or the rearrangement of old nodes necessary?

B. Is this value lower than the threshold estimated in stage 11 ?

C. Is there any other combination of fuzzy rules registered?

D. Is there any other combination of final events registered?

E. Is the trial successful?

F. Is a certain increase of the tolerability of the top event feasible?

G. Is the analytical performance of the sensor satisfactory and suitable for its intended use?

The tree is structured in a top-down direction by deduction (stage 4), involving the identification of the events or series of events that directly contribute to the top event, the immediate causes of these events and so forth, until the ultimate or final causes are identified. Conversely, a revision can be made by induction (stage 7), after proper information has been collected (stage 5). This dialectic trade-off between deduction and induction brings the tree design closer to scientific logic, permitting the introduction of deeper knowledge into the surface or experiential knowledge level characterizing FTA.

Once the final form (in content and architecture) of the fault tree has been agreed upon (stage 6), the partitioning of the space of variables and the determination of the fuzzy rules serving as an inference engine for diagnosis (stages 8 and 9) can been achieved by using experts' opinion through a modified four-stage Delphi method. Running the fuzzy FTA bottom-up (stage 13), using first the combination of the final events that contributes mostly (as per strength and frequency) to the top event, a crisp number is calculated for the latter and compared with the specified threshold (stage 10). Similarly, based on a nested loop mechanism described by the decision nodes C and D, the most influential combination responsible for the top event is experimentally confirmed (stage 17) and, if possible, rectified; otherwise, the next combination is examined (stage 11), and so on until the value of the top event reaches the threshold. The selectivity of research is thereby enhanced considerably by concentrating attention to the most influential variables, consequently saving resources and increasing research value. In case of a satisfactory remediation, the device, re-engineered at stage 18, is forwarded to clinical testing (stage 19).

The internal KB (stage 20) is the backbone of the procedure and has been developed to support case-based or model-based or rules-based reasoning to facilitate device (re-) engineering and serve online fault diagnostics. Such an integration will effectively assist sensor design to assure the successful development of the final product according to predetermined specifications. The formalism adopted herein is quite flexible to allow for handling a wide range of different cases within this complex and dynamic science-based sector.

\subsection{The content/trunk-tree part}

Sensor sensitivity is a controversial term. It usually implies the slope of the calibration curve in the vicinity of the expected real measurement, a function of analyte concentration or amount $[24,25]$; as such it can be defined as either the minimum input signal required to produce a specific output, given a certain signal-to-noise ratio, or as the ratio of the signal output for a given concentration to the signal obtained for an adjacent concentration value $(C \pm 1)$. This property is very crucial, especially towards the limit of detection, where hypoglycaemic episodes should be identified as soon as possible in order for the patient to receive treatment, as well as for the identification/location of abrupt glucose changes.

In view of the above, the reduction in sensitivity involves either a responsivity decrease, i.e. a decrease of the output signal in response to input [16], a modification of the analyte flux kinetics 
Table 1: Description of the fault tree nodes of Fig. 3.

\begin{tabular}{|c|c|c|}
\hline Node & Node & Node \\
\hline (1.1) decrease of responsivity & $\begin{array}{l}\text { (1.2.1.1.1) increase of sensor's } \\
\text { membrane hydrophobicity }\end{array}$ & (1.2.2.4.3.2) stress response \\
\hline $\begin{array}{l}\text { (1.2) modification of analyte } \\
\text { flux kinetics }\end{array}$ & (1.2.1.1.2) biofouling & $\begin{array}{l}\text { (1.1.2.1.1.1.1) membrane } \\
\text { stripped during implantation }\end{array}$ \\
\hline $\begin{array}{l}\text { (1.3) poor in vivo/in vitro } \\
\text { correlation }\end{array}$ & $\begin{array}{l}\text { (1.2.1.1.3) tissue encapsulation } \\
\text { of the sensor }\end{array}$ & $\begin{array}{l}\text { (1.1.2.1.1.1.2) large fracture } \\
\text { leading to local rupture }\end{array}$ \\
\hline $\begin{array}{l}\text { (1.1.1) inhibition of enzymatic } \\
\text { reaction }\end{array}$ & $\begin{array}{l}\text { (1.2.1.2.1) decrease of tissue } \\
\mathrm{pH}\end{array}$ & $\begin{array}{l}\text { (1.2.2.2.1.1.1) persisting } \\
\text { inflammation }\end{array}$ \\
\hline $\begin{array}{l}\text { (1.1.2) degeneration of } \\
\text { enzyme }\end{array}$ & $\begin{array}{l}\text { (1.2.1.2.2) increase of tissue } \\
\text { void volume }\end{array}$ & $\begin{array}{l}(1.2 .2 .2 .1 .1 .2) \text { autoimmune } \\
\text { response }\end{array}$ \\
\hline $\begin{array}{l}(1.2 .1) \text { decrease of analyte } \\
\text { influx } \\
\text { to the enzyme }\end{array}$ & $\begin{array}{l}\text { (1.2.2.2.1) increase of adjacent } \\
\text { cells uptake and metabolism }\end{array}$ & $\begin{array}{l}(1 \cdot 2 \cdot 2 \cdot 4 \cdot 1.1 .1) \text { electric field } \\
\text { created around the implant } \\
\text { attracts fibroblasts }\end{array}$ \\
\hline $\begin{array}{l}\text { (1.2.2) alteration of the } \\
\text { absolute analyte concentration }\end{array}$ & $\begin{array}{l}\text { (1.2.2.2.2) endothelial } \\
\text { metabolism (wall effect) }\end{array}$ & $\begin{array}{l}(1.2 .2 .4 \cdot 1.1 .2) \text { increase of } \\
\text { tissue } \mathrm{pH}\end{array}$ \\
\hline (1.2.3) alteration of kinetics & $\begin{array}{l}(1.2 .2 .4 .1) \text { formation of thick } \\
\text { fibrous capsule surrounding } \\
\text { the implant }\end{array}$ & $\begin{array}{l}(1.2 .2 .4 \cdot 1.1 .3) \text { alteration } \\
\text { of oxygen tension at the } \\
\text { peri-implant site }\end{array}$ \\
\hline $\begin{array}{l}\text { (1.3.1) increase of the basal } \\
\text { sensor current }\end{array}$ & $\begin{array}{l}\text { (1.2.2.4.2) insufficient } \\
\text { vascularization of the fibrous } \\
\text { capsule surrounding the } \\
\text { implant }\end{array}$ & $\begin{array}{l}(1.2 .2 .4 .3 .2 .1) \text { increase in the } \\
\text { hormonal release }\end{array}$ \\
\hline (1.3.2) decrease of the & \multirow{3}{*}{\multicolumn{2}{|c|}{$\begin{array}{ll}\text { (1.2.2.4.3) rapid changes in blood } & (1.2 .2 .4 .3 .2 .2) \text { increase of } \\
\text { glucose alteration } & \text { lipid metabolism } \\
(1.1 .2 .1 .1 .1) \text { partial } & (1.2 .2 .2 .1 .1 .1 .1) \text { implant } \\
\text { disintegration of sensor's } & \text { movement }\end{array}$}} \\
\hline linearity of response & & \\
\hline $\begin{array}{l}\text { (1.3.3) small frequency of } \\
\text { sensor calibration }\end{array}$ & & \\
\hline (1.1.1.1) oxygen deficit & $\begin{array}{l}\text { (1.1.2.1.1.2) increased influx } \\
\text { of oxygen radicals }\end{array}$ & (1.2.2.2.1.1.1.2) toxic shock \\
\hline $\begin{array}{l}\text { (1.1.1.2) shortage of } \\
\text { supplementary chemicals }\end{array}$ & $\begin{array}{l}\text { (1.2.1.1.1.1) increase sensor- } \\
\text { exudate protein exchange }\end{array}$ & $\begin{array}{l}\text { (1.2.2.2.1.1.1.3) prevention of } \\
\text { wood healing process }\end{array}$ \\
\hline $\begin{array}{l}\text { (1.1.1.3) electrochemical } \\
\text { interference }\end{array}$ & (1.2.1.1.1.2) lipid phase shifts & $\begin{array}{l}\text { (1.2.2.4.1.1.3.1) increase of } \\
\text { oxygen inflow }\end{array}$ \\
\hline (1.1.2.1) enzyme poisoning & $\begin{array}{l}\text { (1.2.1.1.2.1) excessive protein } \\
\text { deposition on membrane pores }\end{array}$ & $\begin{array}{l}\text { (1.2.2.4.1.1.3.2) increase of the } \\
\text { membrane oxygen solubility }\end{array}$ \\
\hline (1.1.2.2) heat shock & $\begin{array}{l}(1.2 .1 .1 .2 .2) \text { thrombus formation } \\
\text { on the sensor surface }\end{array}$ & $\begin{array}{l}\text { (1.2.2.2.1.1.1.1.1) contraction } \\
\text { of the underlying muscle }\end{array}$ \\
\hline $\begin{array}{l}\text { (1.2.1.1) physical barrier to } \\
\text { analyte transport }\end{array}$ & $\begin{array}{l}\text { (1.2.1.2.1.1) increased release } \\
\text { of proteolytic enzymes }\end{array}$ & $\begin{array}{l}\text { (1.2.2.2.1.1.1.1.2) collapse of } \\
\text { the subcutaneous fibres }\end{array}$ \\
\hline $\begin{array}{l}\text { (1.2.1.2) modification at the } \\
\text { peri-implant site }\end{array}$ & $\begin{array}{l}(1.2 .1 .2 .1 .2) \text { increased release } \\
\text { of oxygen radicals }\end{array}$ & $\begin{array}{l}(1.2 \cdot 2 \cdot 2 \cdot 1 \cdot 1 \cdot 1.2 .1) \text { partial } \\
\text { disintegration of sensor's } \\
\text { membrane }\end{array}$ \\
\hline
\end{tabular}


Table 1 (Continued): Description of the fault tree nodes of Fig. 3.

\begin{tabular}{|c|c|c|}
\hline Node & Node & Node \\
\hline $\begin{array}{l}\text { (1.2.2.1) limitation of the } \\
\text { blood supply to the peri- } \\
\text { implant site }\end{array}$ & $\begin{array}{l}\text { (1.2.2.2.1.1) excessive } \\
\text { numbers of inflammatory cells }\end{array}$ & $\begin{array}{l}(1.2 .2 .2 .1 \cdot 1.1 .2 .2) \text { increase in } \\
\text { NO release }\end{array}$ \\
\hline $\begin{array}{l}\text { (1.2.2.2) increased analyte } \\
\text { consumption }\end{array}$ & $\begin{array}{l}(1.2 .2 .2 .1 .2) \text { hormonal } \\
\text { activation }\end{array}$ & $\begin{array}{l}(1.2 .2 \cdot 2 \cdot 1 \cdot 1 \cdot 1.3 .1) \text { decrease in } \\
\text { NO release }\end{array}$ \\
\hline $\begin{array}{l}\text { (1.2.2.3) decrease of vascular } \\
\text { analyte output }\end{array}$ & $\begin{array}{l}\text { (1.2.2.2.2.1) implant touches } \\
\text { the blood vessel wall }\end{array}$ & $\begin{array}{l}(1 \cdot 2 \cdot 2 \cdot 2 \cdot 1 \cdot 1 \cdot 1 \cdot 3 \cdot 2) \text { inhibition } \\
\text { of collagen deposition or/and } \\
\text { cross-linking }\end{array}$ \\
\hline $\begin{array}{l}(1.2 .2 .4) \text { loss of equilibrium } \\
\text { between the exudate and } \\
\text { blood levels }\end{array}$ & $\begin{array}{l}\text { (1.2.2.2.2.2) vasoconstriction } \\
\text { of the underlying artery/vein }\end{array}$ & $\begin{array}{l}(1.2 .2 .4 \cdot 1 \cdot 1.3 .1 .1) \text { increase of } \\
\text { partial oxygen pressure in the } \\
\text { interstitial space }\end{array}$ \\
\hline (1.1.2.1.1) proteolysis & $\begin{array}{l}\text { (1.2.2.4.1.1) increased } \\
\text { fibroblast attachment }\end{array}$ & $\begin{array}{l}(1.2 .2 .4 \cdot 1.1 .3 .1 .2) \\
\text { angiogenesis due to exercise } \\
\text { or pharmaceuticals }\end{array}$ \\
\hline (1.1.2.1.2) degeneration & $(1.2 .2 .4 .1 .2)$ trauma & $\begin{array}{l}\text { (1.2.2.2.1.1.1.2.1.1) increased } \\
\text { leukotriene synthesis by the } \\
\text { activation of the lipogenesis } \\
\text { pathway }\end{array}$ \\
\hline $\begin{array}{l}\text { (1.1.2.2.1) temperature above } \\
37^{\circ} \mathrm{C} \text { for a long period of time }\end{array}$ & (1.2.2.4.3.1) glucose infusion & $\begin{array}{l}(1 \cdot 2 \cdot 2 \cdot 2 \cdot 1 \cdot 1 \cdot 1 \cdot 2 \cdot 1.2) \text { alteration } \\
\text { of tissue matrix at the } \\
\text { peri-implant site }\end{array}$ \\
\hline $\begin{array}{l}(1.1 .2 .2 .2) \text { exothermic } \\
\text { reactions inducing abrupt } \\
\text { temperature increase }\end{array}$ & & \\
\hline
\end{tabular}

(the pumping of glucose from the interstitial fluid in the sensor) [26], or incorrect calibration, especially in in vivolex vivo correlation of glucose levels $[17,18]$. The intermediate events that lead to these second-level events can be located when considering the design, the operation, and the environment of the sensor. The basic biosensor detection scheme implies that a working mode requires [21-25]: (a) the analyte to be able to enter the reaction chamber, via favourite diffusion kinetics, whereas the interferents must be excluded based on diffusion limitations and (b) the analyte entering the reaction chamber must be able to reach the bioreceptor and, under favourite conditions, must be strong enough to enhance proper biomaterial orientation and prevent leakage, yet to react with it; (c) the biomaterial, apart from being specific to the analyte, must retain its full functionality, in order for the reaction to yield the product; (d) the biomaterial/support interactions support must not interact with the functional groups of the biomaterial nor alter its physicochemical state; (e) the reaction product or any by-product must not poison the biomaterial or the support; (f) the product must be effectively transferred to the transducer without scattering, either by crossing the support of via mediators; (g) the transducer shows no drift (e.g. polarized electrode) or fouling; and (h) the analyte or the product is washed off and the functional biomaterial sites are regenerated. Any misfunction of the above is considered critical and can lead to a noisy biosensor, or an inaccurate signal output [16], i.e. each step of biosensing contributes to possible fault generation and its propagation to the secondlevel events $(1.1,1.2$, and 1.3). 


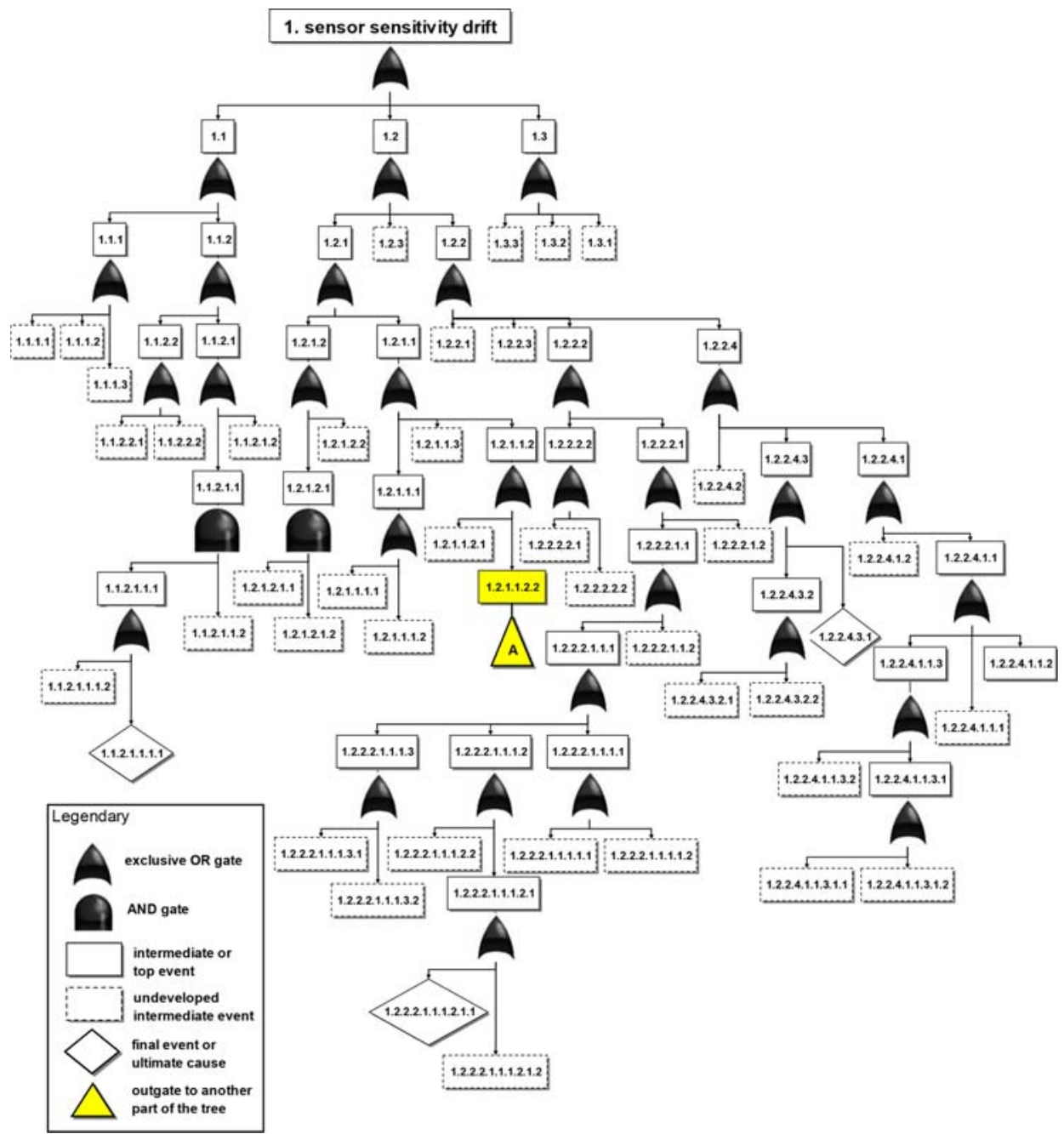

Figure 3: The upper part of the fault tree investigating the causes of sensitivity drift in subcutaneous sensors: the qualitative upper part of the tree constituting the content part of the methodological framework (the formal being the mechanism of setting/revising the fuzzy rules).

\subsection{Fuzzy partition of the space of the variables}

Each tree node has been quantified using ranges of values that could be described by the linguistic terms (fuzzy sets) low, medium, and high. The degree, or weighting, with which any value belongs to a fuzzy set is represented by the membership function; over their domain of interest/validity, the membership functions take a value between 0 and 1 ; each term is schematically presented as a triangle, peaking at the value that the node-event is most commonly found (membership function 1). The overlapping of the space of variables depends on the uncertainty of the measure or effect of the event. Working in the bottom-up mode within the tree-like structure, the quantification of each node depends 
on its direct sub-ordinates, considering (a) their value and (b) the degree of their contribution to the node. This relation is given by a series of fuzzy rules that determine the output of the node as fuzzy set. The basal events (ultimate causes) are entered as fuzzy numbers or as crisp values and their fuzzy output enters subsequently the direct upward intermediate event/node, which is thus quantified, and so forth until a fuzzy number produced for quantifying the top event; after defuzzification, a crisp value is obtained to serve as a more meaningful term in common vocabulary. Similarly, all fuzzy numbers produced by the inference engine and assigned to each intermediate event may appear as crisp values, to illustrate the fault influence/propagation along the corresponding path.

\section{IMPLEMENTATION AND RESULTS}

The methodology described above has been implemented in node 1.2.1.1.2.2, 'thrombus formation on the sensor surface' (branch A of Fig. 3), one of the most commonly encountered problem in implanted materials $[12,13]$ : the thrombus covers the sensor surface inhibiting glucose diffusion. Following stages 3 and 5 of the algorithmic procedure (Fig. 2), an extensive literature search provided various causes for this event. The reactions of the body to an implant crucially depends on the surface of the implant [27], especially the chemical situation present at the surface [13], the surface texture [27], the local flow conditions [26], as well as other factors. An extract of the relevant tree is presented in Fig. 4 (stage 4). It is generally agreed that the 'increased platelet adhesion, activation and aggregation' (node A2.1.1) on implant surfaces exposed precede the formation of the thrombus [28]. Therefore, in vitro analysis of these properties is usually performed as a first test of the haemocompatibility of a surface. Additionally, the platelet morphology (circularity and area) can be taken as an indication of the ability of the surface to support thrombus formation. A high ratio of the proteins albumin/fibrinogen, adsorbed on an implant surface prior to cell or platelet attachment, can be correlated with a low number of adhering platelets and therefore with low tendency of thrombus formation [28]. However, some materials may show contradicting results when implanted, as shown for polyurethane and parylene [29].

Despite, however, the directly related physiological reasons that contribute to the top even, implant failure can be triggered by seemingly unrelated reasons that necessitated the extension of the tree (stage 7). For example, 'increased calcium' (node A2.1.2.1.2.1.2.1.2.2.1) or 'vitamin C' (node A2.1.2.1.2.1.2.1.1.1) intake [30-32], 'vitamin A deficiency' (node A2.1.2.1.2.1.2.2.2) [33], or 'hypercholesterolaemia' (node A2.1.2.1.2.1.2.2.1.1) [34] have been identified as deeper-level mechanismic contributors to thrombus formation. High calcium could be of significant importance, since most type II patients suffer from severe osteoporosis (node A2.1.2.1.2.1.2.1.2.2.1.1), requiring chronic treatment. Also, adenocarcinomas (node A2.1.2.1.2.1.2.1.2.2.2.1) are very common to male patients above 50 years of age [35], not to mention the high incidence of thyroid hormone-related diseases worldwide (node A2.1.2.1.2.1.2.1.2.2.2.2) [36], both of which potentially lead to pathogenic hypercalcaemia.

A sample of the fuzzy rules used (stage 9), representing a chain leading from the 18-digit final event A2.1.2.1.2.1.2.1.2.2.1.1 to the 6-digit intermediate event A, used herein as pseudo-top event for inference (the highlighted part of Fig. 4), is presented below:

IFA.1.2.1.2.1.2.1.2.2.1 is [low]ANDA.1.2.1.2.1.2.1.2.2.2 is [medium] THENA.1.2.1.2.1.2.2.2 is $[$ medium].

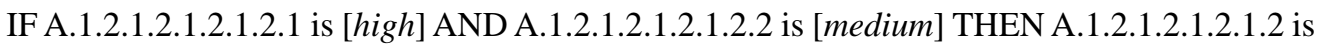
[high].

IF A.1.2.1.2.1.1.1 is [low] AND A.1.2.1.2.1.2. 1 is [high] THEN A.1.2.1.2.1.2. is [medium]. IF A.1.2.1.2.1.2.1 is [medium] AND A.1.2.1.2.1.2.2 is [low] THEN A.1.2.1.2.1.2 is [low].

IF A.1.2.1.2.1.1 is [high] AND A.1.2.1.2.1.2 is [low] THEN A.1.2.1.2.1 is [medium]. 


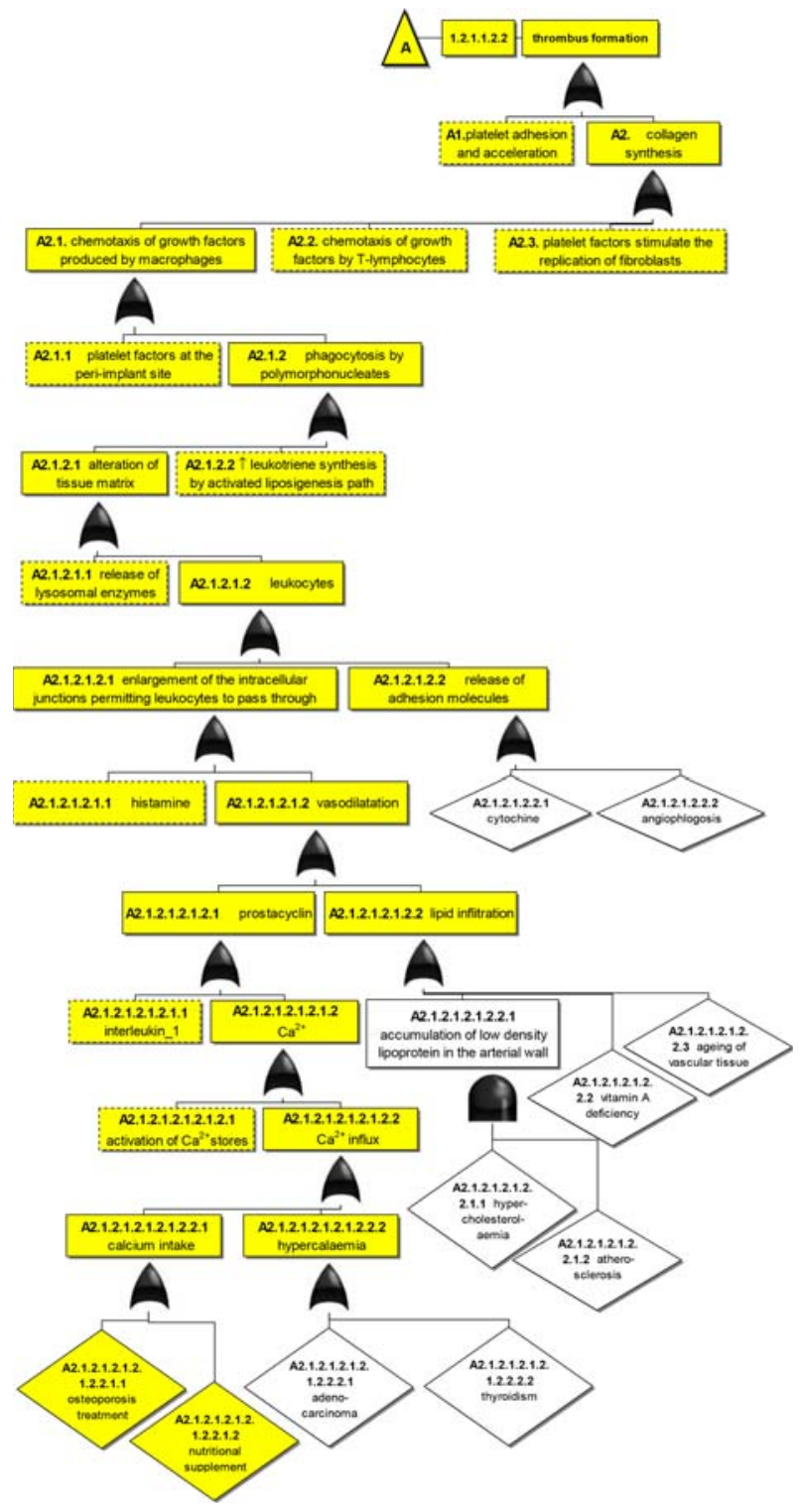

Figure 4: Extract from the fault tree on 'thrombus formation on the sensor surface'.

The threshold value, $T$, set for the 'top event' (stage 10) is $20 \%$, as proven suitable for retaining much of sensor's functionality. The problem investigated refers mainly to the effect of calcium intake by the subject upon the sensor performance, considering, also, other parallel physiological processes (stage 13). Nine scenarios have been tested (Table 2) aiming at examining all possible combinations and influences (the highlighted part of Fig. 4). The results have shown that at any value of the basal event (cases 1-3), the top event is well below the tolerance value, provided that all other inputs are kept low. There is a slight increase in the top event-value when the "calcium stores are 
Table 2: The degree and extent of contribution of some of the parameters that directly or indirectly lead to thrombus formation on the sensor surface (node A), estimated through the inference achieved by the chain of fuzzy rules, leading from the basal event of node A2.1.2.1.2.1.2.1.2.2.1.1 to the top event.

\begin{tabular}{lrrrrrrrrr}
\hline Node no. & 1 & \multicolumn{1}{c}{2} & \multicolumn{1}{c}{3} & \multicolumn{1}{c}{4} & 5 & 6 & 7 & 8 & 9 \\
\hline A2.1.2.1.2.1.2.1.2.2.1.1 & 180 & 550 & 1200 & 180 & 1200 & 180 & 180 & 250 & 180 \\
A2.1.2.1.2.1.2.1.2.2.2 & 5 & 5 & 5 & 5 & 5 & 5 & 5 & 5 & 30 \\
A2.1.2.1.2.1.2.1.2.1 & 8 & 8 & 8 & 50 & 8 & 8 & 8 & 8 & 100 \\
A2.1.2.1.2.1.2.1.1 & 4 & 4 & 4 & 4 & 4 & 4 & 4 & 4 & 50 \\
A2.1.2.1.2.1.2. & 6 & 6 & 6 & 6 & 70 & 10 & 10 & 10 & 30 \\
A2.1.2.1.2.1.1 & 1 & 1 & 1 & 1 & 1 & 18 & 160 & 18 & 18 \\
A2.1.2.1.2.2 & 4 & 4 & 4 & 4 & 4 & 4 & 4 & 4 & 40 \\
A2.1.2.1.1 & 2 & 2 & 2 & 2 & 2 & 2 & 2 & 2 & 30 \\
A2.1.2.2 & 6 & 6 & 6 & 6 & 6 & 6 & 6 & 6 & 50 \\
A2.1.1 & 4 & 4 & 4 & 4 & 4 & 4 & 4 & 4 & 20 \\
A2.2 & 12 & 12 & 12 & 12 & 12 & 12 & 12 & 12 & 20 \\
A2.3 & 14 & 14 & 14 & 14 & 14 & 14 & 14 & 14 & 50 \\
A1 & 8 & 8 & 8 & 8 & 8 & 8 & 8 & 8 & 50 \\
Output of A (1.2.1.1.2.2) & 7.33 & 7.52 & 7.65 & 7.98 & 7.85 & 22.67 & 22.89 & 22.91 & 63.61 \\
\hline
\end{tabular}

activated' (node A2.1.2.1.2.1.2.1.2) (case 4), as well as, at 'increased lipid infiltration' (node A2.1.2.1.2.1.2.2) (case 5), mainly due to 'high cholesterol levels' (node A2.1.2.1.2.1.2.2.1.1). The effect of high blood cholesterol is as significant as expected, since it has been often accused for inducing ex vivo sensor fouling [37]. The latter (cases 6-8), even at medium values can induce the vast formation of thrombus on the sensor surface [6], resulting at values above the set threshold. It can be thus concluded that after implantation, the cholesterol and histamine blood levels should be carefully monitored at a regular basis to prevent thrombogenic activity. Case 9 examines the possibility that all inputs assume medium values, a situation common at elder patients suffering from the long-term disease complications, where the value of the top event is well above threshold (Fig. 5). It thus appears that subcutaneous sensors could not be used in this group, unless maintained under intensive drug therapy, a prospect that may not be always possible or could not improve the life quality of these patients. R\&D efforts should be, therefore, focused at improving the anti-thrombogenic properties of the sensor's surface, employing new coating materials, to reduce adverse effects.

Working similarly, the results of this study have been classified to short- and medium-term implications of sensor implants. The medium-term problems involve: (a) technological drawbacks, especially on the rate transmission of the biochemical information to the transduction system (lower event of node 1.3.1 in Fig. 3); current research on nanotechnology platforms is expected to solve miscommunication issues and lag times [38, 39]; (b) sample matrix effects, especially related to signal accuracy due to cholesterol levels (node A2.1.2.1.2.1.2.2.1 in Fig. 4), haematocrit variations, hyperbaric conditions, and some dialysis drugs such as icodextrin (lower events not shown linked to node 1.2.2.4 in Fig. 3); these problems have been also identified in ex vivo testing and could be dealt with correction algorithms and multi-sensing [40]; (c) poor in vivo/in vitro correlation (node 1.3 in Fig. 3); current approaches focus on in vivo calibration and the use of suitable reference matrix 

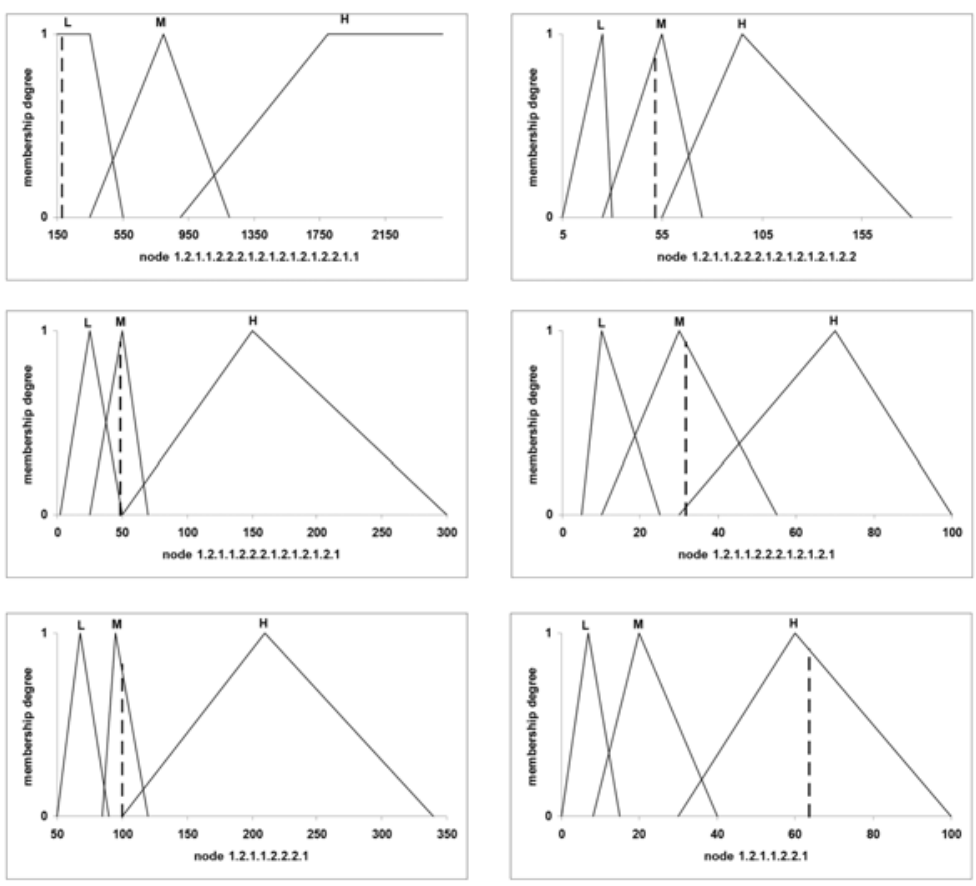

Figure 5. Membership function of some of the variables participating within the fuzzy chain leading from the final event 1.2.1.1.2.2.2.1.2.1.2.1.2.1.2.2.1.1 (increased calcium intake by the subject as a treatment course for osteoporosis) to the top event 1.2.1.1.2.2 (thrombus formation on the sensor surface), when all other input variables are in the medium range. The dashed line represents output values (Case 9 of Table 2), except from the basal event (input value).

materials for ex vivo analytical development [18]; (d) responsivity problems (node 1.1) related to oxygen tension variability, especially due to decreased blood volume (lower event not shown linked to node 1.1.1.1 in Fig. 3) resulting either from microhaemorrhages or from a concurrent infection; enzyme degradation (node 1.1.2) is, also, a significant contributor to the top event, especially when linked to radical attack as a result of low anti-oxidant activity; the employment of microperfusion techniques is expected to improve performance [41].

Regarding the short-term problems, inflammation and thrombus formation (nodes 1.2.2.2.1.1.1 and 1.2.1.1.2.2, respectively in Fig. 3) have been highlighted as the major contributors. Both are known and expected; they are system disturbance errors, i.e. the sensor disturbs the environment in which it operates, and probably the best way to deal with them is by engineering the device to release anti-inflammatory chemicals such as nitric oxide [42]. Notwithstanding, the inference engine revealed that there exist some underlying conditions, common in diabetics, that may speed up, enhance, or extend these reactions. Inflammation has been linked to vasoconstriction due to training, dehydration, or increased supplement intake (especially calcium), whereas thrombus formation is enhanced by anxiety treatment, asthma drugs, and various hormonal problems. These results imply that any drugs included in the device should be decided on an individual basis, and their efficacy should be closely monitored. 


\section{DISCUSSION}

The results presented refer to the identification and investigation of the factors (external and/or inherent to biosensing) that alone or in synergy cause sensitivity decrease, in a way that uncertainty of measurement or rectification of performance can be considered more efficiently and less costly. The incorporation of fuzzy logic in the presented framework facilitates the decision making in R\&D with limited information under high uncertainty. Such a tool can effectively serve its purpose in focusing research towards solving or preventing significant problems, until more information is available from clinical trials of the devices or basic biochemical research. As the KB (stage 20 of the algorithmic procedure in Fig. 3) is continually enriched, fuzzy rules are revised, narrowing overlapping and increasing the accuracy and reliability of the results. It is worthwhile noting that current knowledge stored in the KB includes many hypothetical or understudied cellular and biochemical mechanisms that should be further elucidated to reduce uncertainty; for example, the primary role of calcium on the modulation of pyruvate dehydrogenase (PDH) phosphorylation could either mediate translocation of the phosphatase to the E2 component of PDH complex [26] or diminishes ATP production by lowering inner membrane voltage [30]; the fault tree supports both branches, activating the one that each time is proven more intense or dominant. Moreover, the methodology proposed can help in the knowledge elucidation of the clinical aspects of the disease, especially at issues of debate. For example, when sensor misfunctioning is found (after appropriate testing) to be caused by 'thrombus formation on the sensor surface' (node A) which is in turn attributed to 'decreased release of nitric oxide' (lower event not shown linked to node A1.3 in Fig. 4), the cause of the latter should be identified to apply the appropriate remedies; NO synthesis is inhibited by two possible disjunctive pathways, either the activation of the polyol cycle [41] or the impairment of iron regulation [42]. The clarification of the mechanisms that regulate this interaction is, on one hand, essential to fault compensation, and on the other hand, it may contribute significantly to the improvement of diabetes management and its possible complications.

\section{CONCLUSIONS}

The method presented herein serves effectively to localize the causes of sensor drift in subcutaneous biosensors under conditions of uncertainty. When coupled to fuzzy reasoning, it provides a suitable platform for developing online sensor diagnostics and fault compensation. The development and maintenance of a KB facilitates a multi-faceted applicability of the proposed tool. For example, it enhances selectivity of R\&D effort by concentrating attention to the most influential variables, thus enabling the distinction between critical and non-critical errors. Although the results provided cannot be fully validated under real-operation, they do hold a significant predictive value. Most importantly, this work has highlighted a shifting in sensor design protocols towards ad hoc customised sensor development, thus potentiating the progress of epidemics from statistics to individualization.

\section{REFERENCES}

[1] Vashist, S.K., Zheng, D., Al-Rubeaan, K., Luong, J.H.T. \& Sheu, F-S., Technology behind commercial devices for blood glucose monitoring in diabetes management: a review. Analytica Chimica Acta, 703, pp. 124-136, 2011. doi: http://dx.doi.org/10.1016/j.aca.2011.07.024

[2] Shaw, J.E., Sicree, R.A. \& Zimmet, P.Z., Global estimates of the prevalence of diabetes for 2010 and 2030. Diabetes Research and Clinical Practice, 87, pp. 4-14. 2010.doi: http://dx.doi. org/10.1016/j.diabres.2009.10.007

[3] Yoo, E-H. \& Lee, S-Y., Glucose biosensors: an overview of use in clinical practice. Sensors, 10, pp. 4558-4576, 2010. doi: http://dx.doi.org/10.3390/s100504558 
[4] D'Orazio, P., Biosensors in clinical chemistry - 2011 update. Clinica Chimica Acta, 412, pp. 1749-1761, 2011. doi: http://dx.doi.org/10.1016/j.cca.2011.06.025

[5] Gerritsen, M., Jansen, J.A. \& Lutterman, J.A., Performance of subcutaneously implanted glucose sensors for continuous monitoring. The Netherlands Journal of Medicine, 54, pp. 167-179, 1999. doi: http://dx.doi.org/10.1016/S0300-2977(99)00006-6

[6] Klueh, U., Dorsky, D.I. \& Kreutzer, D.L., Enhancement of implantable glucose sensor function in vivo using gene transfer-induced neovascularization. Biomaterials, 26, pp. 1155-1163, 2005. doi: http://dx.doi.org/10.1016/j.biomaterials.2004.04.017

[7] Cobelli, C. \& Ruggeri, A., Evaluation of portal/peripheral route and of algorithms for insulin delivery in the closed-loop control of glucose in diabetes - a modeling study. IEEE Transactions on Biomedical Engineering, 30, pp. 93-103, 1983. doi: http://dx.doi.org/10.1109/ TBME.1983.325203

[8] Klonoff, D.C., The benefits of implanted glucose sensors. Journal of Diabetes Science and Technology, 1(6), pp. 797-800, 2007. doi: http://dx.doi.org/10.1177/193229680700100601

[9] Renard, E., Place, J., Cantwell, M., Chevassus, H. \& Palerm, C.C., Closed-loop insulin delivery using a subcutaneous glucose sensor and intraperitoneal insulin delivery. Diabetes Care, 33(1), pp. 121-127, 2010. doi: http://dx.doi.org/10.2337/dc09-1080

[10] Wickramasinghe, Y., Yang, Y. \& Spencer, S.A., Current problems and potential techniques in in vivo glucose monitoring. Journal of Fluorescence, 14, pp. 513-520, 2004. doi: http://dx.doi. org/10.1023/B:JOFL.0000039339.36839.19

[11] Nablo, B.J., Prichard, H.L., Butler, R.D., Klitzman, B. \& Schoenfisch, M.H., Inhibition of implant-associated infections via nitric oxide release. Biomaterials, 26, pp. 6984-6990, 2005. doi: http://dx.doi.org/10.1016/j.biomaterials.2005.05.017

[12] Sieminski, A.L. \& Gooch, K.J., Biomaterial-microvascalature interactions. Biomaterials, 21, pp. 2233-2241, 2000. doi: http://dx.doi.org/10.1016/S0142-9612(00)00149-6

[13] Faucheux, N., Tzovena, R., Nagel, M.-D. \& Groth, T., The dependence of fibrillar adhesions in human fibroblasts on substratum chemistry. Biomaterials, 27, pp. 234-245, 2006. doi: http:// dx.doi.org/10.1016/j.biomaterials.2005.05.076

[14] Wisniewski, N. \& Reichert, M., Methods for reducing biosensor membrane biofouling. Colloids and Surfaces B: Biointerfaces, 18, pp. 197-219, 2000. doi: http://dx.doi.org/10.1016/ $\underline{\text { S0927-7765(99)00148-4 }}$

[15] Kasemo, B., Biological surface science. Current Opinion in Solid State and Materials Science, 3, pp. 451-459, 1998. doi: http://dx.doi.org/10.1016/S1359-0286(98)80006-5

[16] Batzias, F.A. \& Siontorou, C.G., Investigating the causes of biosensor SNR decrease by means of fault tree analysis. IEEE Transactions on Instrumentation and Measurement, 54, pp. 1395-1406, 2005. doi: http://dx.doi.org/10.1109/TIM.2005.851056

[17] Abrahamsson, P. \& Winsö, O., An assessment of calibration and performance of the microdialysis system. Journal of Pharmaceutical and Biomedical Analysis, 39, pp. 730-734, 2005. doi: http://dx.doi.org/10.1016/j.jpba.2005.04.036

[18] Jeong, R.-A., Hwang, J.Y., Joo, S., Chung, T.D., Park, S., Kang, S.K., Lee, W.-Y. \& Kim, H.C., In vivo calibration of the subcutaneous amperometric glucose sensors using a nonenzyme electrode. Biosensors and Bioelectronics, 19, pp. 131-139, 2003. doi: http://dx.doi. org/10.1016/S0956-5663(03)00219-7

[19] Banerjee, R., Nag, S. \& Fraser, H.L., A novel combinatorial approach to the development of beta titanium alloys for orthopaedic implants. Materials Science and Engineering $C, \mathbf{2 5}$, pp. 282-289, 2005. doi: http://dx.doi.org/10.1016/j.msec.2004.12.010 
[20] Bellazzi, R., Guglielmann, R. \& Ironi, L., Learning from biomedical time series through the integration of qualitative models and fuzzy systems. Artificial Intelligence in Medicine, 21, pp. 215-220, 2001. doi: http://dx.doi.org/10.1016/S0933-3657(00)00088-9

[21] Siontorou, C.G., Batzias, F.A. \& Tsakiri, V., A knowledge-based approach to online fault diagnosis of FET biosensors. IEEE Transactions on Instrumentation and Measurement, 59, pp. 2345-2364, 2010. doi: http://dx.doi.org/10.1109/TIM.2009.2036464

[22] Siontorou, C.G. \& Batzias, F.A., Error identification/propagation/remediation in biomonitoring surveys - a knowledge-based approach towards standardization via fault tree analysis. Ecological Indicators, 11, pp. 564-581, 2011. doi: http://dx.doi.org/10.1016/j.ecolind.2010.07.013

[23] Siontorou, C.G. \& Batzias, F.A., Carbohydrate detection failure analysis via biosensoring. IEEE Transactions on Instrumentation and Measurement, 57, pp. 2856-2867, 2011. doi: http://dx.doi.org/10.1109/TIM.2008.926051

[24] Thévenot, D.R., Toth, K., Durst, R.A. \& Wilson, G.S., Electrochemical biosensors: recommended definition and classification. Pure and Applied Chemistry, 71, pp. 2333-2348, 1999. doi: http://dx.doi.org/10.1351/pac199971122333

[25] Usher, M.J., Sensors and Transducers. Macmillan: London, UK, 1985.

[26] Wisniewski, N., Rajamand, N., Adamsson, U., Lins, P.E., Reichert, W.M., Klitzman, B. \& Ungerstedt, U., Analyte flux through chronically implanted subcutaneous polyamide membranes differs in humans and rats. American Journal of Physiology, Endocrinology and Metabolism, 282, pp. E1316-E1323, 2002.

[27] Berglin, M., Andersson, M., Sellborn, A. \& Elwing, H., The effect of substrate molecular mobility on surface induced immune complement activation and blood plasma coagulation. Biomaterials, 25, pp. 4581-4590, 2004. doi: http://dx.doi.org/10.1016/j.biomaterials.2003.11.050

[28] Theoret, C.L., Update on would repair. Clinical Techniques in Equine Practice, 3(2), pp. 110-122, 2004. doi: http://dx.doi.org/10.1053/j.ctep.2004.08.009

[29] Weisenberg, B.A. \& Mooradian, D.L., Hemocompatibility of materials used in microelectromechanical systems: platelet adhesion and morphology in vitro. Journal of Biomedical Materials Research, 60(2), pp. 283-291, 2002. doi: http://dx.doi.org/10.1002/jbm.10076

[30] Choi, J., Hammer, L.W. \& Hester, R.L., Calcium-dependent synthesis of prostacyclin in ATPstimulated venous endothelial cells. Hypertension, 39, pp. 581-585, 2002. doi: http://dx.doi. org/10.1161/hy0202.103289

[31] Deng, T., Yu, L., Ge, Y., Zhang, L. \& Zheng, X., Intracellular-free calcium dynamics and F-actin alteration in the formation of macrophage foam cells. Biochemical and Biophysical Research Communications, 338, pp. 748-756, 2005. doi: http://dx.doi.org/10.1016/j.bbrc.2005.10.010

[32] Beetens, J.R., Coene, M.C., Verheyen, A., Zonnekeyn, L. \& Herman, A.G., Vitamin C increases the prostacyclin production and decreases the vascular lesions in experimental atherosclerosis in rabbits. Prostagladins, 32(3), pp. 335-352, 1986.

[33] Brattsand, R., Actions of vitamins A and E and some nicotinic acid derivatives on plasma lipids and on lipid infiltration of aorta in cholesterol-fed rabbits. Atherosclerosis, 22, pp. 47-61, 1975. doi: http://dx.doi.org/10.1016/0021-9150(75)90067-2

[34] Knobler, H., Savion, N., Shenkman, B., Kotev-Emeth, S. \& Varon, D., Shear-induced platelet adhesion and aggregation on subendothelium are increased in diabetic patients. Thrombosis Research, 90, pp. 181-190, 1998. doi: http://dx.doi.org/10.1016/S0049-3848(98)00050-4

[35] Zimering, M.B. \& Thakker-Varia, S., Increased fibroblast growth factor-like autoantibodies in serum from a subset of patients with cancer-associated hypercalcemia. Life Sciences, 71, pp. 2939-2959, 2002. doi: http://dx.doi.org/10.1016/S0024-3205(02)02160-4 
[36] Sourbier, C. \& Massfelder, T., Parathyroid hormone-related protein in human renal cell carcinoma. Cancer Letters, 240(2), pp. 170-182, 2006. doi: http://dx.doi.org/10.1016/j.canlet.2005.08.020

[37] Zhang, S., Wright, G. \& Yang, Y., Materials and techniques for electrochemical biosensor design and construction. Biosensors and Bioelectronics, 15, pp. 273-282, 2000. doi: http:// dx.doi.org/10.1016/S0956-5663(00)00076-2

[38] McWilliams, A., Microsensors: MEMS, biosensors and nanosensors. Code - IAS027A. Category - Instrumentation and Sensors. BCC Research, April 2008.

[39] Rajaram, S., Sensors: technologies and global markets. Code - IAS006D. Category Instrumentation and Sensors. BCC Research, March 2011.

[40] Siontorou, C.G. \& Batzias, F.A., Innovation in biotechnology: moving from academic research to product development - the case of biosensors. Critical Reviews in Biotechnology, 30, pp. 79-98, 2010. doi: http://dx.doi.org/10.3109/07388550903427298

[41] Piechotta G., Albers, J. \& Hintsche, R., Novel micromachined silicon sensor for continuous glucose monitoring. Biosensors and Bioelectronics, 21, pp. 802-808, 2005. doi: http://dx.doi. org/10.1016/j.bios.2005.02.008

[42] Schoenfisch, M.H., Mowery, K.A., Rader, M.V., Baliga, N., Wahr, J.A. \& Meyerhoff, M.E., Improving thromboresistivity of chemical sensors via nitric oxide release: fabrication and in vivo evaluation of NO-releasing oxygen-sensing catheters. Analytical Chemistry, 72, pp. 11191126, 2000. doi: http://dx.doi.org/10.1021/ac991370c 